\title{
Maxillo-mandibular rehabilitations with very early osteointegrated dental implants for severe hypodontia and anodontia related to ectodermal dysplasia
}

\author{
Philippe Martin, Christian Paulus
}

Hôpital Femme Mère Enfant, Service de Chirurgie Maxillo-Faciale et Stomatologie Pédiatriques, Lyon, France

Email: docteurpaulus@paulus-richard.com

Received 10 August 2012; revised 12 September 2012; accepted 18 September 2012

\begin{abstract}
The ectodermal dysplasias are rare diseases with hypodontia, hypotrichosis and hypohidrosis. The subject's life is considerably constrained and this from an early age, with major difficulties for the integration and acceptance of conventional prosthetic occlusal rehabilitation. The use of implants is an integral part of early treatment, in the regions of stable growth, that is to say symphysis. In two childs of $\mathbf{5}$ and 6 years we have made implant-borne prosthetic rehabilitation in the maxilla and the mandible. Aesthetic and social evaluation were positive. We have restored the normal oro-facial functions for the correct development of skeletal bases. They acted as an external fixator intraoral, stimulating the growth by the function. Our question was: can we leave a child throughout his childhood and adolescence with a not suitable removable prosthesis, under the pretext of growth unfinished?
\end{abstract}

Keywords: Ectodermal Dysplasia; Anodontia; Hypodontia; Osteointegrated Dental Implants; Facial Growth

\section{DEFINITIONS}

ECTODERMAL DYSPLASIAS (E.D.) a heterogeneous group of diseases characterized by developmental abnormalities of ectodermal structures. Approximately 160 genetically and clinically distinct E.D. have been identified. 111 forms include dental abnormalities.

PINHEIRO, FREIRE MAIA were the first to try to classify E.Ds in 1994 [1].

It was determined that a disease could be classified as an E.D. if it has two symptoms affecting one of four relevant structures: hair, teeth, nails and sweat glands.

Therefore, hypotrichosis, hypodontia, onychodysplasia and hypohidrosis are the principal symptoms to more or less marked degrees.
This classification is based on clinical signs and symptoms as the pathogenesis and molecular genetics remain relatively unknown [2].

Their frequency is estimated at 1 in 7 for every 100,000 births with all forms combined [1].

The combination of hypohidrosis, hypotrichosis and hypodontia is known as CHRIST SIEMENS TOURAINE syndrome, an X-linked recessive inheritance disorder.

Heterozygous females whose $\mathrm{X}$ chromosome carries the mutation transmit the disease.

They are called XLHED carriers.

There is often a vital severe hyperthermia in young children with this particular form.

CLASTON syndrome, autosomal dominant, includes hypotrichosis, hypodontia and abnormal nail growth.

During the physical examination, additional oral symptoms include:

- Hypopigmented dry skin.

- Presence of perioral and peri-orbital wrinkles with hyper pigmentation.

- Eczema dermatitis.

- Rare, fine and brittle hair, eyelashes and eyebrows.

- Malformed nails.

- Enlarged lips.

- Smell and taste disorders.

- Recurrent respiratory infections.

Intraoral symptoms are:

- Dysmorphosis of anterior teeth (small, conoid, and pointy).

- Often severe abnormalities affecting deciduous and permanent teeth.

The subject's life is considerably impaired from an early age, with major problems concerning the integration and acceptance of conventional occlusal prosthesis dental treatments.

\section{MATERIALS AND METHODS}

Alexandre was born on 13th February 2003 and was first brought into our Department of Maxillofacial Surgery 
and Paediatric Dentistry in January 2005 (2 years and 11 months) for absence of teeth.

He was referred to us by his paediatrician.

The clinical examination and X-ray assessment (panoramic X-ray and frontal plus lateral teleradiography) enabled us to diagnose ectodermal dysplasia (Figures 1-3).

The intra-oral examination revealed the presence of three conoid canines in 233343.

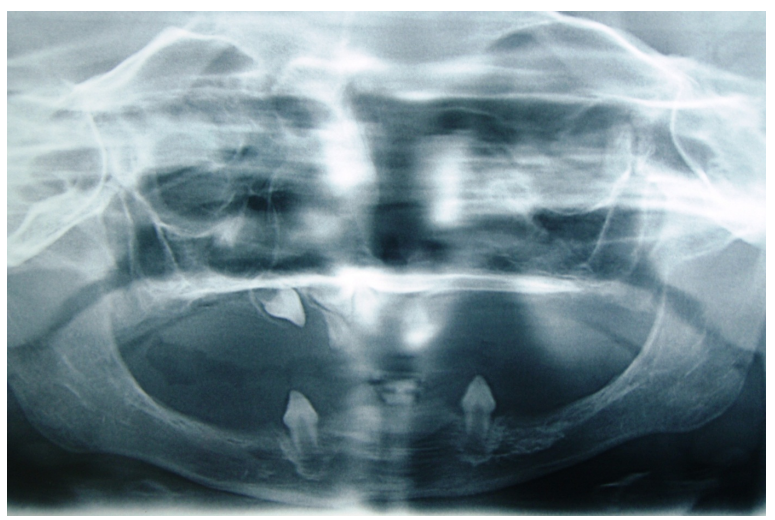

Figure 1. Initial dental panoramic [X-ray].

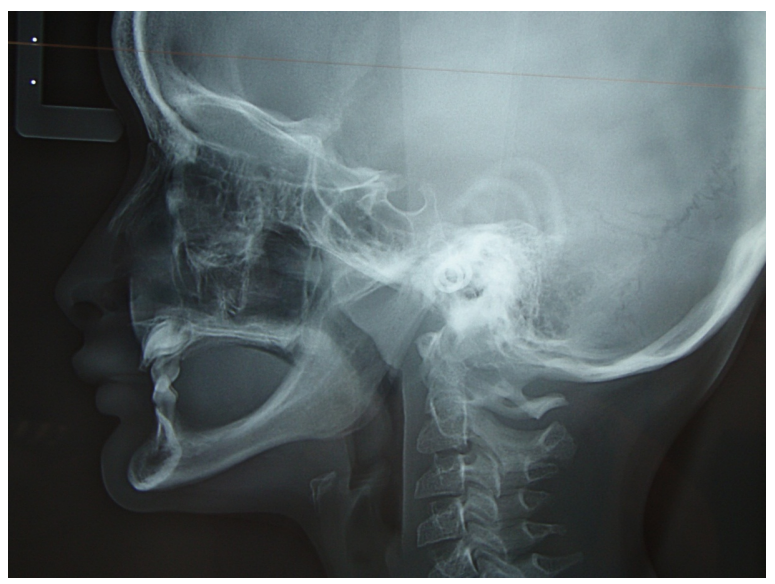

Figure 2. Profile teleradiography.

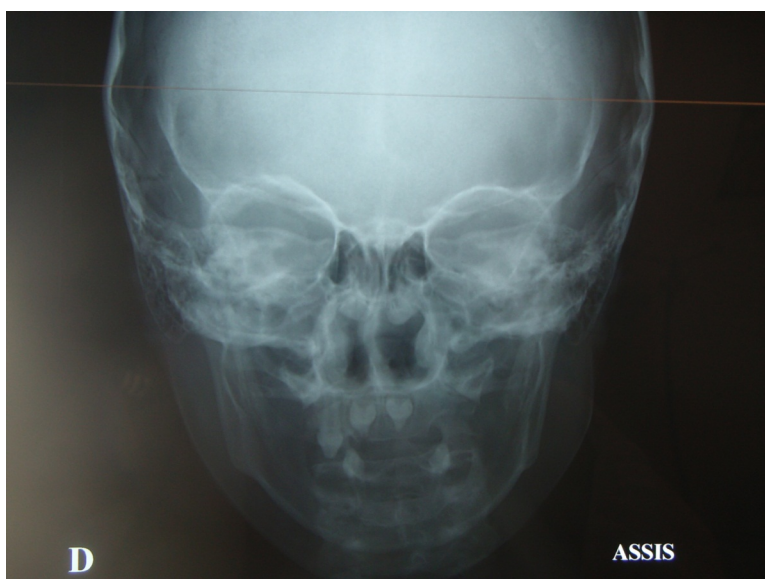

Figure 3. Facial teleradiography.
The X-ray examination made it possible to see two dysmorphic germs in 11 and 21.

The extraoral examination showed a thin and dry skin, with perioral and periorbital fine wrinkles, periorbital hyperpigmentation, fine and rare hair, and angular cheilitis on the labial commissures.

The issues of hyperthermia were mentioned by the parents and confirmed the diagnosis of anhidrotic ectodermal dysplasia.

The family is highly expectant and the various possible therapies were outlined to them. The difficulties in placement removable dentures and their acceptance by the child were explained to them. The use of implants was discussed.

The situation was explained to Alexandre, who was sitting in the armchair, so that he can slowly get used to the unit and the treatment he will receive.

Removable devices were then made for him but the child and his parents seem reluctant and find acceptance difficult.

The lack of stability of the prostheses support led us to perform several relinings and to redo them several times (2006-2007-2008).

Candida albicans mycosis was diagnosed at the mucosal level next to the prosthetic lower surface. This has been treated with FUNGIZONE but contributed somewhat more to the rejection of the devices.

An implant consultation was arranged in December 2008. The provisional nature of and the risks involved in such treatment were clearly presented and explained to the parents. The benefits and disadvantages were discussed.

In June 2009, Alexandre was 6 years old. He underwent a surgical operation under general anaesthesia at the Femme Mère Enfant Hospital in Lyon.

Nasotracheal intubation, extra and intra oral asepsis with PIVODONE IODINE (BETADINE).

\section{- Mandible:}

33 and 43 were extracted. An incision was performed on the edentulous ridge and discharges in front of the anterior edges of the rami.

Mucoperiosteal elevation and exposure of the chin foramina.

Regularisation of the ridge with a gouge and a round bur.

Between 34 and 44: drilling and screwing of five implants diameter $3.4 \mathrm{~mm}$ length $13 \mathrm{~mm}$ (PROGRESS SF${ }^{\circ}$, TEKKA)

Autogenous bone graft on the buccal and lingual mandibular symphysis with bone trapped through a filter.

Closure with VICRYL 3/0 and three months healing.

\section{- Maxilla:}

Incision on the top of the edentulous ridge and retro tuberosity discharges. 
Muco periosteal undermining .

Extraction of 13 and buds included of 21 and 11.

Exposure of thin alveolar ridges and the anterior lateral wall of right and left maxillary sinuses.

Regularization of ridges with forceps and construction of two windows with gouge at the level of the canine fossa.

Tilting of bone flap in the sinus and dissection of the sinus mucosa. Sinuses at this stage are poorly developed.

Drilling and screwing of seven implants (PROGRESS SF TEKKA-France).

Three implants diameter 4 mm length 13 in 131416 .

Two implants diameter 3.4 mm length 13 in 2324 .

Two implants diameter 3.4 mm length 10 in 11 and 26.

Intra-sinus bone grafts, as well as in vestibular and palatal maxillary and peri implant, with a mixture of autogenous bone and bank bone (OSTEOPUR Etablissement Français du Sang $3500 \mu<15 \mathrm{~cm}^{3}$ ) are performed.

Scarification of the muco-periosteum.

Closure in two layers with VICRYL 3/0.

Healing 8 to 10 months (Figure 4).

The following drugs were administered intravenously during surgery:

AUGMENTIN $100 \mathrm{mg} / \mathrm{kg}$ a day.

SOLUMEDROL $3 \mathrm{mg} / \mathrm{kg}$.

PRO DAFALGAN.

The patient was discharged with:

AUGMENTIN $80 \mathrm{mg} / \mathrm{kg}$ in three divided doses for ten days.

PREDNISOLONE 5-2 tablets morning and evening for three days.

DAFALGAN $15 \mathrm{mg} / \mathrm{kg}$ in case of pain every six hours CHLOREXIDINE mouthwash.

The removable dentures were rehabilitated and rebased. Alexandre could wear them during the healing phase of the implants.

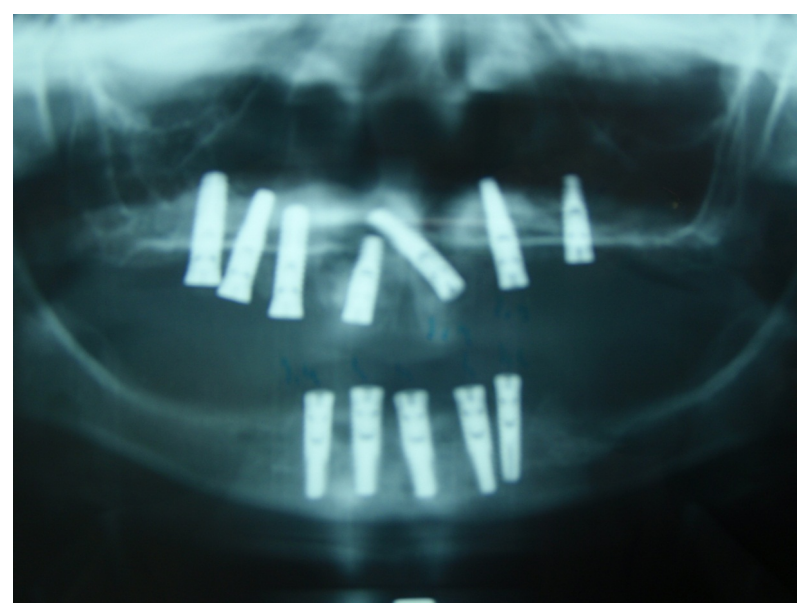

Figure 4. View after surgery.
After waiting four months, we have decided to put the mandibular implants to use. Under general anaesthesia we have exposed the implants. Incision on the edentulous ridge, and full thickness elevation of the flap and exposure of implant heads.

The implants have been tested and the locking screws were removed.

Introduction of multi-conical abutments (transgingival ring $3 \mathrm{~mm}$ high) in the implants (Figure 5).

Transfers (pick up) are tightened in the mouth on the abutments for the impression. We have used heavy silicone impression material in the open tray previously tailored by the laboratory, and light silicone around the transfers (Figure 6).

After setting the material, the screw implant transfers have been unscrewed and the impression is removed (Figure 7).

The vertical dimension has been taken using bite wax developed in the laboratory.

The gingival healing screws are put in place on multiconical abutments.

The prosthesis concept was a BRANEMARK-type bridge screwed in five implants (Figures 8-11).

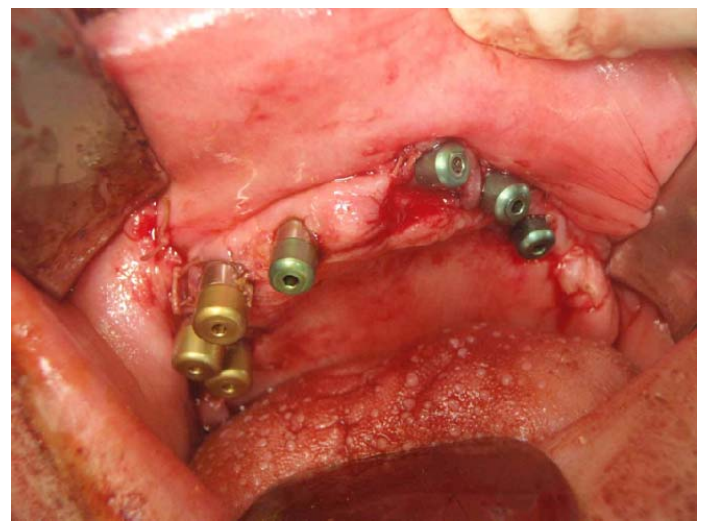

Figure 5. Exposure of maxillar implants and placement of multi-conical implant abutments.

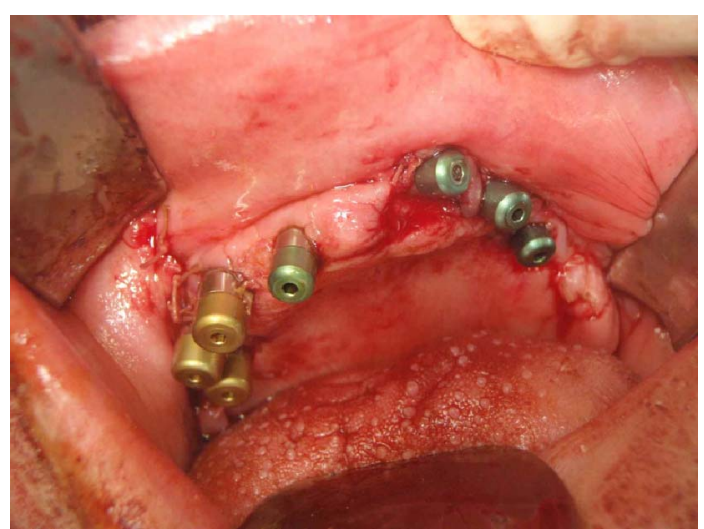

Figure 6. Screwing of the maxillar implant impression copings. 


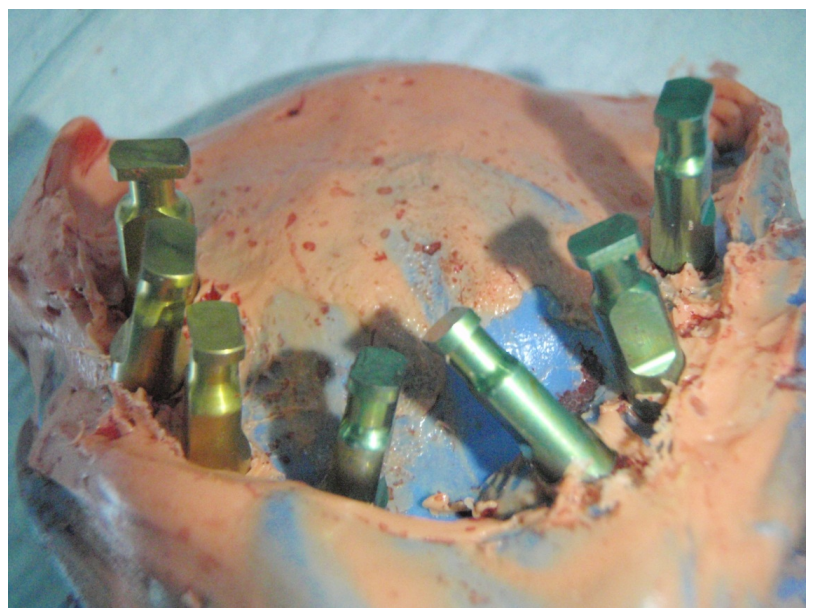

Figure 7. Maxillar impressions.

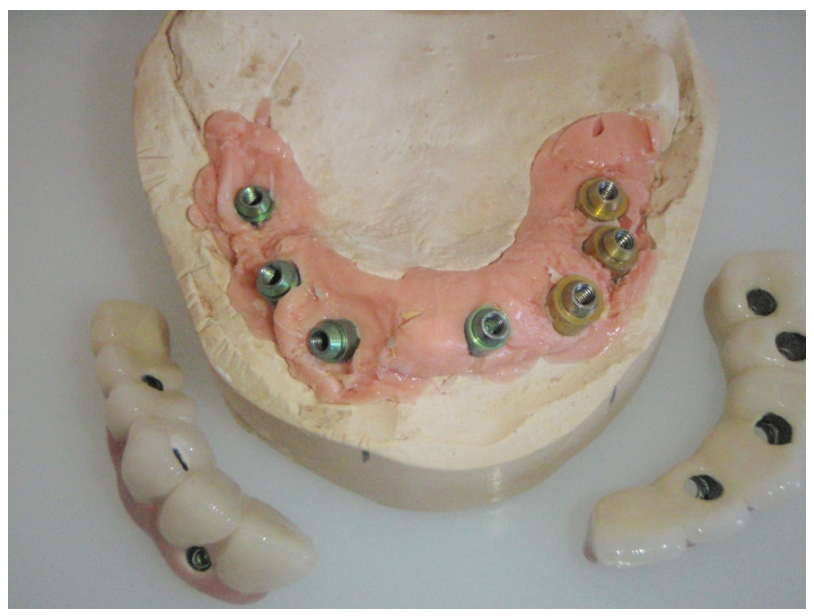

(a)

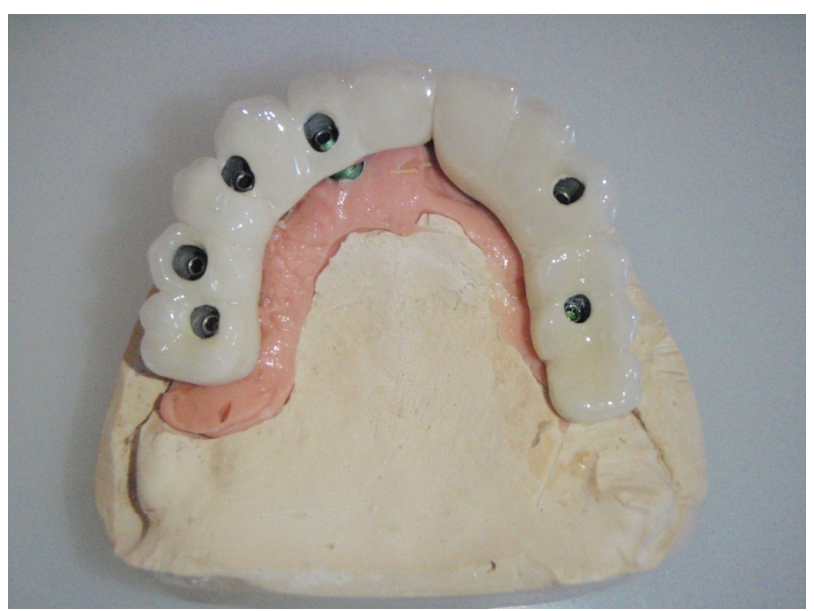

(b)

Figure 8. (a), (b) Screw-retained maxillar bridge on the master model.

For the maxilla, two half screw-retained implant supported bridges have been made leaving the palatal suture free for the transversal growth of the maxilla.

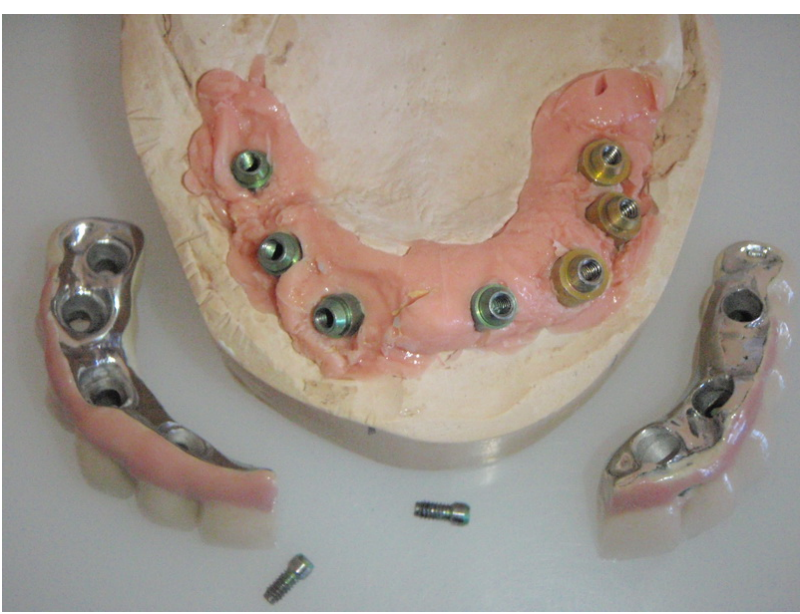

Figure 9. Implant replicas on the laboratory model.

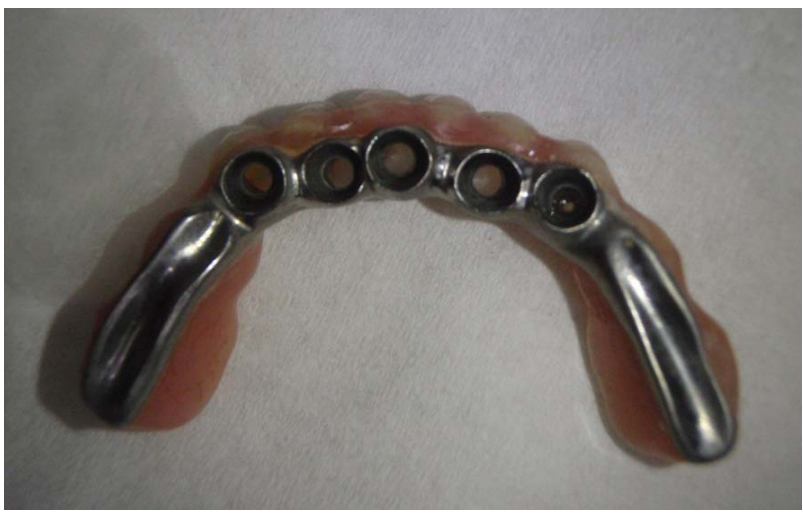

Figure 10. Screw-retained mandibular (intrados) bridge.

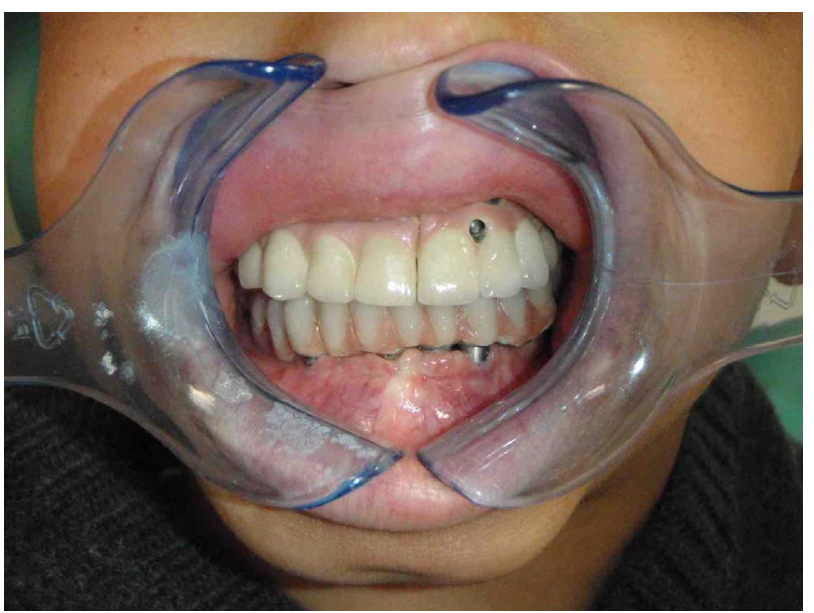

Figure 11. Screw-retained bridge in mouth.

\section{RESULTS}

In spite of unfavourable anatomical sites (fine alveolar crests; jaw and mandible hypotrophics) no implant was lost. Both prostheses not having been realized at the same time, the removable prosthesis complete jaw broke itself repeatedly. This demonstrates the resumption of the 


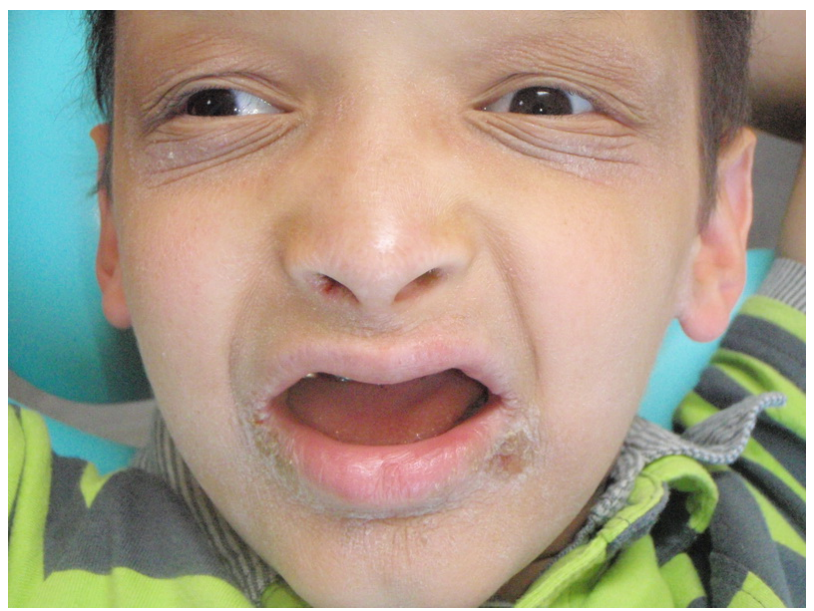

Figure 12. Alexandre before placement of the maxillary implant bridge.

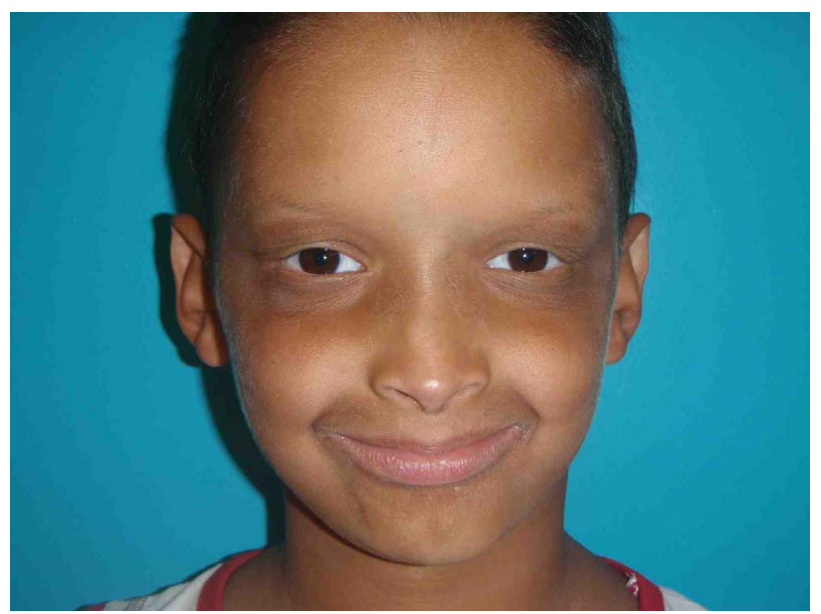

(a)

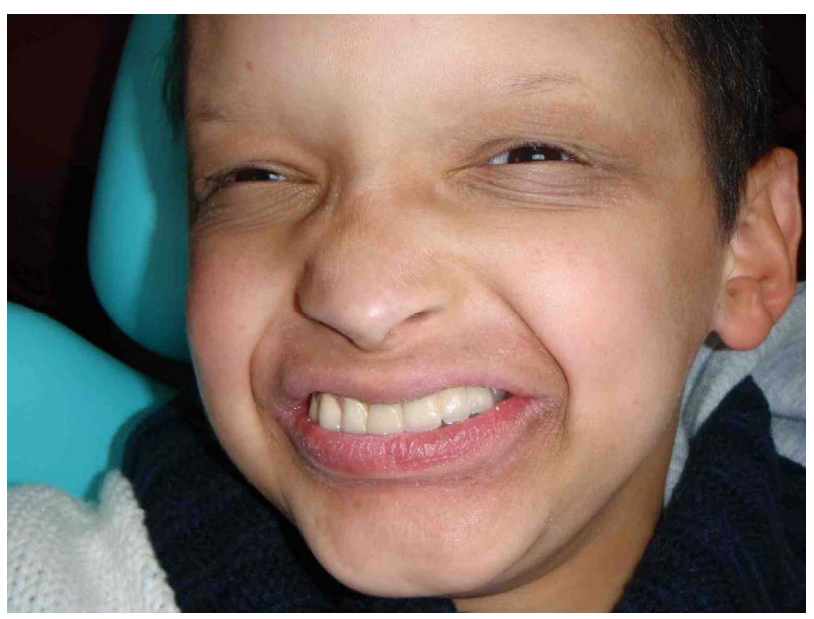

(b)

Figure 13. (a) (b) Alexandre after placement of the maxillary implant bridge.

muscular activity and thus the function since the mandibular prosthesis in place.

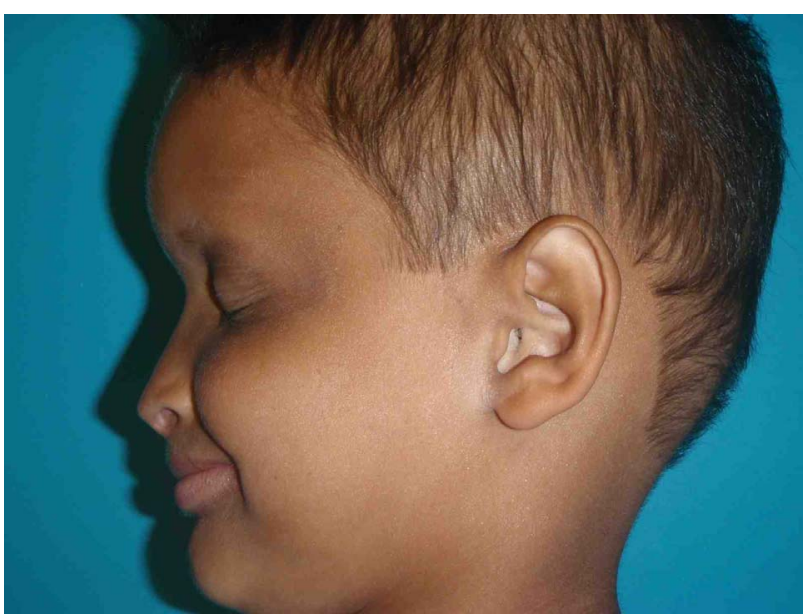

(a)

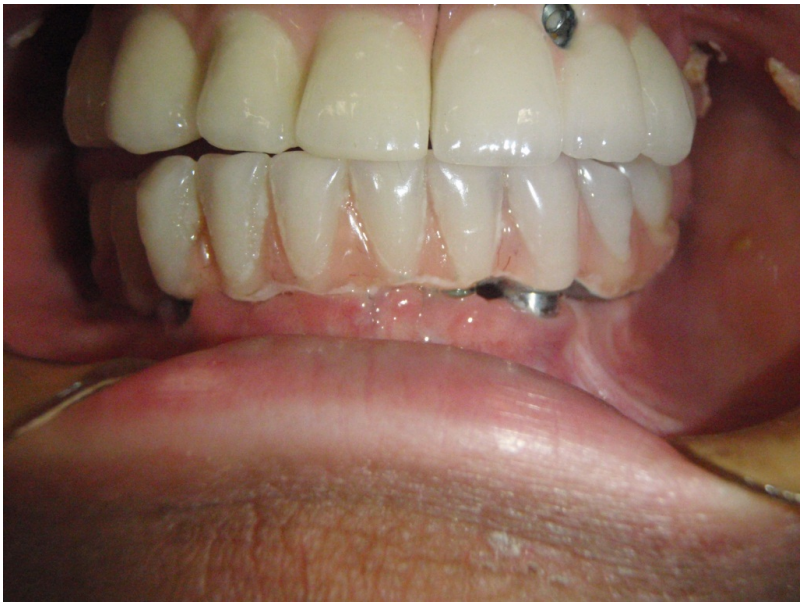

(b)

Figure 14. (a) Alexandre's Profile; (b) Prosthesis in the mouth.

- Functional assessment: we think we can stimulate potential growth of the lower third of the face wich is in sleep mode by restoring the various oro-facial functions. We realize some implanto-facial orthopaedics by stimulating the skeleton and by pulling at the not ossified osseous sutures. Implants and their prostheses can be so compared with distractors on which the soft and continuous strengths of the oral function apply to stimulate and direct the growth.

We have so restored the chewing ability in this child (he could finally eat meat) and we are participating in the growth of his face and weight-for-stature.

- Phonetic assessment

Phonation is normal. There is no retarded speech.

Neither lingual interposition nor infant deglutition can be noticed.

- Aesthetic assessment

Labial connections are normal. Inadequate vertical is cleared, as well as angular cheilitis and perioral wrinkles.

- Social assessment 


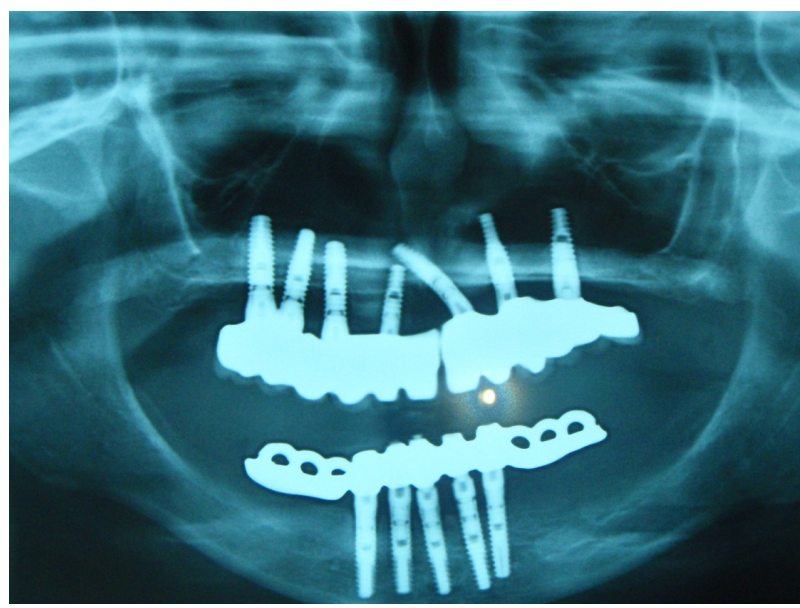

(a)

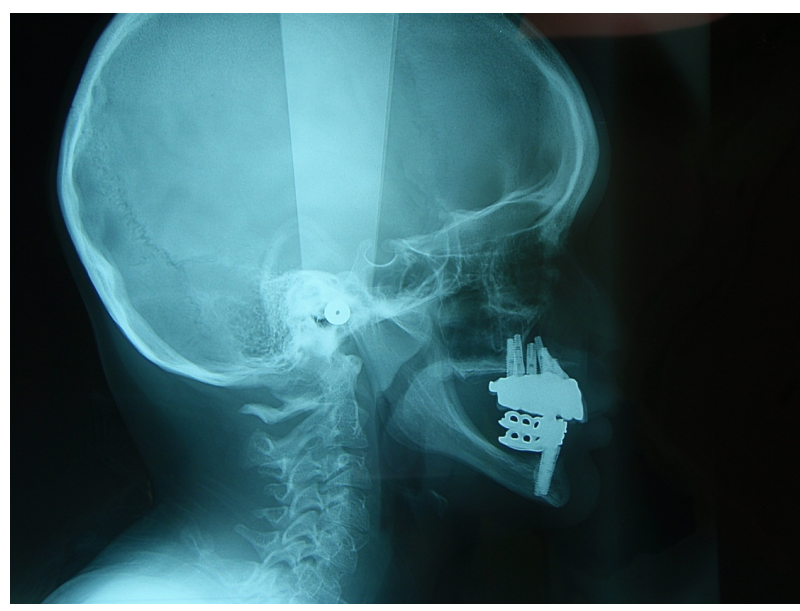

(b)

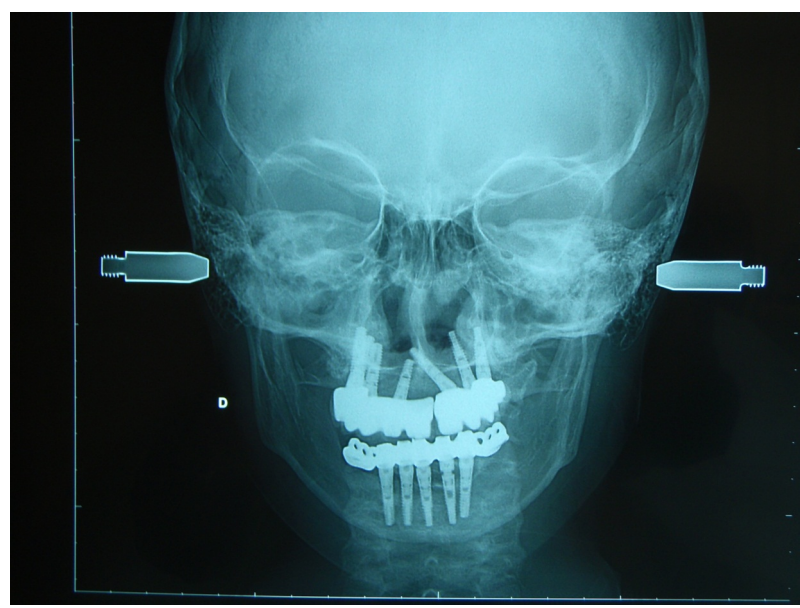

(c)

Figure 15. (a), (b), (c) Placement maxillary and mandibular prosthesis X-rays.

The child is calmer and more confident. He goes to school normally.

He is 8 and passed to third year primary school. He no longer has relationship problems.

\section{- Prosthetic assessment}

Alexandre finds his prostheses comfortable, aesthetic and above all effective.

He seems to pay attention to his dental hygiene and is motivated.

- Growth assessment

Radiological assessment with skull tele X-ray of face and profile has been prescribed every three months.

A cephalometric study will be conducted to evaluate facial growth (mandibular sagittal growth, evolution of SNA, skeletal class relationship).

Growth in the vertical sagittal and transverse directions will be assessed.

Stability and integration of implants will be checked.

The evolution, position (intrusion or extrusion), modification of the axes and their behaviour in relation to growth will be closely monitored (Figures 12-15).

\section{DISCUSSION}

\subsection{Overview of Facial Growth}

1) Growth of the maxilla

- Sagittal growth

Initial growth is passively downwards and forward due to the growth of the skull supporting the maxilla (one third of growth at 7 years of age).

Then, there is active growth when the bone structure develops (two thirds of growth).

This growth is variable: $2.5 \mathrm{~mm}$ for incisors and $4 \mathrm{~mm}$ for molars.

The orbital floor is reshaped upwards, while the nasal floor is reshaped downwards by cortical remodeling.

- Transverse growth

This initially occurs via an increase in the cranial vault, on the median suture, then via the growth of the palatal suture; this process stops when the palatal suture closes at fifteen years of age.

Transverse growth is three times the sagittal growth.

- Vertical growth

The growth is the result of the alveolar bone development associated with the arrival of teeth.

There is also a resorption of the nasal floor. Vertical growth in the maxilla is the largest, it extends until the permanent teeth are in occlusion.

2) Growth of the mandibula

- Sagittal and vertical growth

We have a postero-superior condyle growth and posterior growth of the ramus with resorption of the anterior margin and apposition on its posterior margin.

The vector is, therefore, upwards and toward the back.

The symphyseal region is stabilized before the eruption of deciduous teeth. A resorption phenomenon follows above the chin during adolescence.

- Transverse growth 
This begins in the posterior region, and is due to the mandibles lengthening into a V-shape. The symphyseal region is already stable by three years of age.

\subsection{Implantology and Bone Growth}

An understanding of maxilla-mandibular growth is important before considering the implant option for a young patient. In the literature, most studies advise waiting until the end of growth before inserting dental implants in children. The implant option may be considered after fifteen years of age for females and 18 years of age for males [3].

Bjork et al. [4] studied facial growth in males from 4 years old to adulthood with the help of strategically placed metal implants in the maxilla (anterior zygomatic apophysis of the maxilla and anterior nasal spine).

Annual radiographic tests from the age of 4 to 21 years old help to analyze bone growth in the three planes.

Animal studies have corroborated these findings. The implants do not follow tooth movements during growth.

They behave like ankylosed teeth which finish up elevated and palatal in the maxilla, the bone remodeling by apposition-resorption gradually buries the coronal part of the implant and exposes the apex.

It finishes up in a low and lingual position for posterior mandibular regions. In the anterior mandibular sectors (symphysis) there is a slight movement of implants.

Many authors report clinical cases with implants used in children and adolescents [5-8].

All these studies show progressive burial due to vertical growth and a palatal position due to sagittal and transverse growth of the maxilla. They note an infraocclusion of the implant-supported crown, and bone loss for adjacent teeth if there is a nearby natural root implant. Normal vertical alveolar growth for adjacent teeth explains the formation of peri-implant infra-bony defects. Changes in the mandibular angle may eventually change the axis of symphyseal implants. The prognosis of implants between the mental foramina is more favorable; however, the implant supported prostheses need to be monitored and changed depending on growth.

Thereby approval and validation is given by the Haute Autorité de Santé (H.A.S.) [9] [French National Health Authority] for implants (two or four maximum) in the treatment of dental agenesis in children with oligodontia, only in the anterior mandibular region, who are older than six years of age until the end of growth, following failure or intolerance of conventional prostheses.

The functional, aesthetic and psychological benefits are considerable compared to traditional methods.

A long-term study [10] assessed the tolerance of implant supported prostheses, their social interest, the strength and stability of implants and the growth of the face over five years.

The implants were inserted very early at five years old. They concluded that with a major hypodontia, especially mandibular hypodontia, fixtures become essential to create stability.

These implants should be considered as perhaps temporary; however, alongside the risk, the benefit is considerable and there are only very low side effects. The use of fixed prostheses which join the implants of the maxilla should be avoided in children due to the major risk of serious disturbances in transverse growth, especially if the two half arches are connected [3].

Similarly for Guckes et al. [11] and Pigno et al. [12] an implantation at an early age has the potential to result in infra-occlusions, and the joining of several implants together is likely to affect subsequent growth. These authors recommend starting maxillary implant treatment once when growth has finished.

Several details, however, do not seem to point in the same direction as these conclusions.

- The absence of long-term monitoring in these patients limits the value of information on the future of these implants.

- The differences in growth from one individual to another makes it difficult to assess the amount of growth in a patient.

- These studies relate to partially edentoulous patients, surrounded by natural teeth.

The growth observed is different and does not take into account the hypofunction generated by major hypodontias encountered in certain rare diseases (ectodermal dysplasia, Downs S) and which lead to severe clinical situations.

The treatment is the result of an overall maxilla-facial therapy to obtain improved chewing performance and thereby improved growth [13].

Children with E.D. have a cranio-facial dysmorphia, like hypoplasia and retrognathic maxilla with frontal prominence. Hypoplasia of the zygomatic process in the upper position is also observed.

Agenesis does not prevent minimal growth of the basal bone. The morphology of the middle third of the face depends on masticatory forces and pressures that are transmitted to the base of the skull. However, the absence of toth buds contributes to the hypodevelopment of vertical skeletal foundations.

Maxillas with anodontia do not form alveolar processes and vertical maxillary growth is hindered.

In the transverse direction, the palatal suture is stimulated by swallowing, chewing and breathing, but the stimulation of bone structures is low in the event of hypofunction.

The hypotonic lips and the lower position of the tongue spread between the arches do not promote the growth of 
skeletal bases [14].

Cephalometry shows a pseudo mandibular prognathism, an anterior mandibular rotation, and a reduced lower facial height and gonial angle.

The collapse of the occlusal plane, the loss of vertical dimension, and the lack of maxillomandibular growth leads to elderly features.

\subsection{Occluso-Prosthesis Treatment and Rehabilitation with Early Implantology}

The morphology of thin, atretic alveolar ridges, in both the mandible and maxilla, lack of strong stabilization areas, skeletal bases with a tendency to class III, and the loss of vertical dimension, make it difficult to make and adapt functional and aesthetic dentures.

If there are a few conoid teeth in the arch in the anterior sector, these can be used as support hooks for a removable denture.

These teeth will eventually be crowned to be more retentive for the hooks (possibility to use various attachments, drilling, telescopic caps). Molars can be used if present.

However, if the hypodontia is severe or poorly distributed, what can we offer to these ill equipped young patients and their parents at loose ends?

Should we wait for the maxillary growth to end (15 years old in girls and 18 years old in boys) and let the bone structure be resorbed? Should we stimulate growth by restoring function as early as possible?

Should we restore confidence in these children by acting quickly to improve their social integration and avoid psychological and educational delays?

The future of potential implants in these toothless maxillary and mandibular bone structures with little growth is certainly completely different and may need to be reconsidered.

In a study and case presentation, Menetray et al. [15] propose a certainly interesting implantation in the atrophic posterior mandible areas, with two osteosynthesis plate implants and three symphyseal implants to achieve a mandibular screw-retained, implant-supported fixed prosthesis.

However, the proposed solutions are delayed, until growth has finished, which leaves the patient with a fully removable denture throughout their childhood and adolescence and with resultant prejudice they may endure.

The maxillary prosthesis also remains a removable denture as hypodontia is partial.

KIENER et al. [16] have reported a case of E.D. that they had rehabilitated using stable hybrid prostheses. (crowns on natural teeth and removable dentures) at the age of 20 years old - the patient being forced to live with removable prostheses from 7 years old.

In a study, Fotso et al. [17] have shown prosthetic re- habilitation with implants in a brother and sister with A.E.D.: removable dentures are clipped to the fixture in the mandible at 14 years old, in order to finally move onto a fixed solution with additional implants being inserted.

Autogenous bone grafts in the anterior sectors are performed and fixed prostheses are inserted on the maxilla. They concluded that dental implantation before the end of growth is one solution for reconstructing a functional set of teeth in the event of A.E.D.

Kramer et al. [8] are treating an 8 year old child with A.E.D. by inserting two symphyseal implants. An implant-supported removable denture is then made.

In a lecture at the national convention for the FOUNDATION FOR ECTODERMAL DYSPLASIAS-NF.E.D. given by Dr Brigitta BERGENDAL (Jönköping Dental Institute in Sweden)-A.F.D.E review October 2010questions were answered about early implantation in children with rare diseases:

Q: Can implants be inserted onto the bone during growth?

A: Current knowledge suggests that success is possible in healthy children.

Q: Are there any contraindications for these implants in young patients?

A: Given the current knowledge, there are no contraindications other than those which are commonly known.

Q: What is the best age to insert implants in young patients?

A: There is no set age. In the case of anodontia or severe oligodontia, implants can be inserted before puberty.

Q: What are the advantages and disadvantages of inserting dental implants in growing individuals with regards to alveolar development, craniofacial growth and short- and long-term prospects, function and aesthetics?

A: In the case of anodontia, dental implants enable adequate oral function and improve aesthetics, which reduces psychosocial distress. There is no known disadvantages compared to other treatment methods.

\section{CONCLUSIONS}

Medical and dental treatment for children with an E.D is complex and long-term. It requires close collaboration between specialists from different fields (surgeons, implantologists, orthodontists, ENT speech therapists, psychologists, prosthetists). This multidisciplinary approach allows us to move towards stable, comfortable and aesthetic occlusal prosthesis treatment, which helps to solve the problems of social integration for these children.

In the case of severe hypodontia, early dental implantation will help stabilize, or even fix, functionally unusable complete or partial removable dentures, and thereby call for proper growth by muscle activity and regained 
functions.

Functional, psychological and aesthetic disorders have increased and social integration is again possible.

Some studies recount the monitoring of early implantation in stable growth zones (symphysis mandibulae).

The family must be informed about the known hazards and risks. However, given the significant benefits and reduced risks, all studies considered have helped their patients.

Studies on the maxilla are rare or nonexistent.

Can we leave a child to go through their entire childhood and adolescence with an inappropriate removable denture under the pretext of unfinished growth?

The fact that the maxilla in these children is already resorbed and atretic by massive agenesis, a hypofunction and wearing an inappropriate removable denture, offer little growth potential.

Our implants inserted in these resorbed maxillas will play their "external fixing" role, stimulating growth by function (orthopedic facial implant).

We can also use a these fixtures for transverse maxillary disjonction if desired.

A radiological test (frontal, lateral and a panoramic teleradiograph) every three months should be performed on the patient to see the growth gain by cephalometry and to monitor the behavior of any implants.

The family is requesting proposals for treatment so that their child has a normal social integration and is less different to the other children. Parents should be aware of the complications that may be encountered: lack of integration of implants, progressive burial, changes in the axis and the position of the axis, and surgical redo procedures (removal of implants, bone grafting, orthognathic surgery and new implant insertion).

The prosthesis must be considered as provisional.

The risks may be significant but therapeutic issues for the welfare of these children is equally important.

Other longer-term studies are needed to validate this type of treatment and to appreciate the service provided to these patients.

\section{REFERENCES}

[1] Pinheiro, M. and Feire-Maia, N. (1994) Ectodermal dysplasias: A clinical classification and a causal review. American Journal of Medical Genetics, 53, 153-162. doi:10.1002/ajmg.1320530207

[2] Mortier, K. and Wackens, G. (2003) Ectodrmal dysplasia syndrome. Nedtiidscht Tandheelkd, 110, 190-192.

[3] Davarpanah, M., Moon, J.W., Yang, L.R. Celletti, R. and Martinez, H. (1997) Dental implants in the oral rehabilitation of a teenager with hypohidrotic ectodermal dysplasia. The International Journal of Oral \& Maxillofacial Implants, 12, 252-258.

[4] Bjork, A. and Skieller, V. (1977) Growth of the maxilla in three dimensions as revealed radiographically by the implant method. British Journal of Orthodontics, 4, 5364.

[5] Guckes, A.D., Scurria, M.S., King, T.S., McCarthy, G.R. and Brahim, J.S. (2002) Prospective clinical trial of dental implants in persons with ectodermal dysplasia. Journal of Prosthetic Dentistry, 88, 21-25.

[6] Brugnolo, E., Mazzocco, C., Cordioli, G. and Maizoub, Z. (1996) Clinical and radiographic findings following placement of single-tooth implants in young patients-Case reports. The International Journal of Periodontics \& Restorative Dentistry, 16, 421-433.

[7] Thilander, B., Odman, J., Grondahl, K. and Friberg, B. (1994) Osseointegrated implants in adolescents. An alternative in replacing missing teeth? European Journal of Orthodontics, 16, 84-95. doi:10.1093/ejo/16.2.84

[8] Kramer, F.J., Bathge, C. and Tschernitschek, H. (2007) Implants in children with ectodermal dysplasia: A case report and litterature review. Clinical Oral Implants Research, 18, 140-146. doi:10.1111/j.1600-0501.2006.01180.x

[9] Décision du 3 avril 2007 de l’Union nationale des caisses d'assurance maladie relative à la liste des actes et prestations pris en charge par l'assurance maladie. HAS Journal, 2007.

[10] Paulus, C., Hartmann, C. and Martin, P. (2008) Suivi à long terme d'une dysplasie ectodermique avec implants dentaires très précoces. Implantologie Revue Février.

[11] Guckes, A.D., McCarthy, G.R. and Brahim, J. (1997) Use of endo-osseous implants in a 3-year-old child with ectodermal dysplasia: Case report and 5-year follow-up. $\mathrm{Pe}$ diatric Dentistry, 19, 282-285.

[12] Pigno, M.A., Blackman, R.B., Cronin, R.J. and Cavazos, E. (1996) Prosthodontic management of ectodermal dysplasia: A review of the literature. Journal of Prosthetic Dentistry, 76, 541-545. doi:10.1016/S0022-3913(96)90015-3

[13] Soubeyrand, E., Nicolas, J., Labbe, D. Riscala, S., Olive, L., Compore, J.F. and Benateau, H. (2005) Anhidrotic ectodermal dysplasia (AED): Four cases. Revue de Stomatologie et de Chirurgie Maxillo-Faciale, 106, 328-333. doi:10.1016/S0035-1768(05)86055-3

[14] Bonin, B., Saffarzadeh, A., Picard, A., Levy, P., Romeux, G. and Goga, D. (2001) Early implant treatment of a child with anhidrotic ectodermal dysplasia: A propos of a case. Revue de Stomatologie et de Chirurgie Maxillofa-Ciale, 102, 313-318.

[15] Menetray, D., Scortecci, G., Odin, G. and Ansell, A. (2011) Dysplasie ectodermique-Enfants atteints du syndrome de christ-siemens-touraine et implantologie basale. Implantologie Mai, 13, 23.

[16] Kiener, P., Oetterli, M. and Mericske-Stern. R. (2003) Prosthetic rehabilitation in ectodermal dysplasia. Case report. Schweiz Monatsschr Zahnmed, 113, 1076-1089.

[17] Fotso, J., Hugentobler, M., Killiaridis, S. and Richter, M. (2009) Anhidrotic ectodermal dysplasia. Revue de Stomatologie et de Chirurgie Maxillo-Faciale, 110, 50-54. doi:10.1016/j.stomax.2008.10.005 